\title{
Estratégia\&Negócios
}

ISSN 1984-3372

http://www.portaldeperiodicos.unisul.br/index.php/EeN/

\section{QUALIDADE DOS SERVIÇOS EM INDÚSTRIA TÊXTIL: AVALIAÇÃO DE CLIENTES VAREJISTAS}

\section{QUALITY OF SERVICE IN TEXTILE INDUSTRY: EVALUATION OF CUSTOMERS RETAILERS}

\section{Leomar dos Santos}

Professor titular da Universidade Regional de Blumenau - FURB.

E-mail: leomardossantos@gmail.com

\section{Gildo José Koerich}

Faculdade FAE Blumenau

E-mail: qualific4@gmail.com

\section{Tatiana Marceda Bach}

Mestranda em Administração pelo Programa de Pós-Graduação em Administração - PPGAD da Universidade Regional de Blumenau - FURB.

E-mail: tatibach@gmail.com

\section{Silvana Anita Walter}

Professora dos Programas de Pós-Graduação em Administração - PPGAD - Curso de Mestrado em Administração - e Programa de Pós-Graduação em Ciências Contábeis e Administração - PPGCC- Curso de Doutorado em Ciências Contábeis e Administração da Universidade Regional de Blumenau - FURB.

E-mail: silvanaanita.walter@gmail.com

Recebido em 14/12/2011. Aprovado em 03/05/2012. Disponibilizado em 25/05/2012. Avaliado pelo Sistema double blind review

R. eletr. estrat. neg., Florianópolis, v.5, n.1, p. 200-223, jan./abr. 2012 http://portaldeperiodicos.unisul.br/index.php/EeN/index
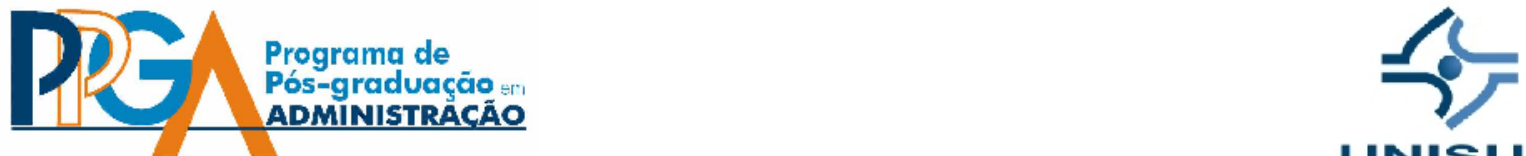

CCopyright 2008 UNISUL-PPGA/Estratégia e Negócios. Todos os direitos reservados. Permitida citação parcial, desde que identificada a fonte. Proibida a reprodução total. Em caso de dúvidas, consulte o editor: ademar.unisul@gmail.com; (48) 3229-193 


\section{RESUMO}

Este estudo objetivou verificar a percepção dos clientes varejistas de uma indústria do setor têxtil a respeito da qualidade dos serviços por ela prestados. Alguns estudos têm investigado a percepção da qualidade de produtos têxteis, porém ainda são incipientes os que analisam a percepção da qualidade dos serviços prestados por essas empresas. Pesquisas dessa natureza tornam-se importantes, pois, além de produzir e comercializar produtos, as indústrias do setor têxtil atuam na prestação de diferentes serviços a seus clientes, mesmo que agregados à venda dos produtos. A qualidade desses serviços pode se tornar um diferencial dessas empresas na satisfação de seus clientes, agregando valor aos produtos. Realizou-se um levantamento, por meio da aplicação de um questionário estruturado, baseado no modelo SERVQUAL, a 130 clientes varejistas de uma empresa têxtil. Para a análise dos dados, empregou-se estatística descritiva para identificar os gaps oriundos da análise deste modelo. O modelo SERVQUAL permitiu identificar os maiores gaps existentes entre expectativa e percepção da qualidade, o que pode auxiliar a empresa a definir prioridades e ações de melhoria. Nesse sentido, apresentaram-se algumas implicações gerenciais na empresa pesquisada. Este estudo também intenciona contribuir para que a empresa implante critérios explícitos de qualidade na prestação de serviços.

Palavras-chave: qualidade dos Serviços. SERVQUAL. Indústria Têxtil.

\section{INTRODUÇÃO}

A indústria têxtil é um dos segmentos que vem enfrentando, nos últimos anos, uma acirrada competição mundial (QUINTELA; MOREIRA; SILVA, 2004), o que tem contribuído para uma redução no número de indústrias no ramo (MASSUDA, 2002). Esse e outros fatores têm impulsionado uma reformulação do setor, o qual vem-se reestruturando progressivamente (MASSUDA, 2002), buscando manter a competitividade, satisfazer os clientes e, consequentemente, sobreviver no mercado (SILVA, 2011). 
Nesse contexto, torna-se fundamental, para as empresas desse setor, manter seus clientes satisfeitos. Para tal, é importante identificar os aspectos que contribuem para a satisfação dos clientes e os aspectos que necessitam ser melhorados visando a essa satisfação. De acordo com Hayes (2001), conhecer as percepções dos clientes auxilia a organização a tomar decisões mais eficazes.

Nesse sentido, embora alguns estudos tenham investigado a percepção da qualidade de produtos têxteis, como os de Quintela, Moreira e Silva (2004) e de Moreira (2004), ainda são incipientes os que analisam a percepção da qualidade dos serviços prestados por essas empresas. Pesquisas dessa natureza, portanto, tornam-se importantes, pois, além de produzirem e comercializarem produtos, as indústrias do setor têxtil atuam na prestação de diferentes serviços a seus clientes, mesmo que agregados à venda dos produtos.

Como exemplos desses serviços prestados aos clientes por indústrias têxteis, destacam-se: atendimento por telefone e internet; atendimento na sede da empresa, para conhecer os produtos e para a realização dos pedidos; portal de informações sobre produtos e acompanhamento dos pedidos; emissão de notas fiscais e duplicatas; entrega dos pedidos; visitas de vendedores à sede dos clientes; fornecimento de informações e material para ações de publicidade; organização de eventos para a apresentação dos produtos; serviços de pós-venda etc. A qualidade de tais serviços pode se tornar um diferencial dessas empresas na obtenção da satisfação de seus clientes, agregando valor aos produtos.

Para auxiliar as empresas a conhecerem as percepções de seus clientes a respeito da qualidade dos serviços que oferecem, existem diferentes modelos: Matriz de Importância versus Desempenho, Modelo Kano de Qualidade, SERQUAL, SERPERF, entre outros. São ferramentas empíricas desenvolvidas pela área de marketing com a finalidade de dar suporte às decisões dos gestores de empresas. Entre os modelos encontrados na literatura, dá-se destaque ao SERVQUAL, desenvolvido e aprimorado ao longo do tempo por Parasuraman, Zeithaml e Berry (1985; 1988). Essa ferramenta considera a qualidade de um serviço como o gap existente entre expectativa e percepção dos clientes. Apesar de existirem críticas a esse modelo (ver CRONIN; TAYLOR, 1992; TEAS, 1994), ele continua 
sendo a ferramenta mais tradicional e amplamente empregada para a mensuração da qualidade percebida de serviços (HUGHEY; CHAWLA; KHAN, 2003; LOPES et al., 2009).

Diante do apresentado, este estudo tem por objetivo analisar qual a percepção dos clientes varejistas de uma indústria do setor têxtil a respeito da qualidade dos serviços por ela prestados. Para tal, emprega-se o modelo SERVQUAL de mensuração da qualidade percebida de serviços. Assim, pretende-se responder à seguinte pergunta de pesquisa: qual a expectativa e a percepção de clientes varejistas de uma centenária companhia têxtil brasileira a respeito da qualidade dos serviços prestados? Esse tema de estudo se mostra relevante para a área de conhecimento, bem como para os gestores das organizações têxteis brasileiras, pois não se encontraram estudos que analisassem a qualidade de serviço nesse ramo.

Este artigo encontra-se estruturado em quatro seções, além desta introdução. Na segunda, apresenta-se a base teórica a respeito dos serviços, da qualidade em serviços e do modelo SERVQUAL; na terceira, destacam-se os procedimentos metodológicos empregados neste estudo; na quarta, descrevem-se os resultados obtidos e, em seguida, fazse sua análise e, por fim, na quinta seção, exibem-se as considerações finais, limitações da pesquisa e sugestões para futuros estudos.

\section{BASE TEÓRICA}

Nesta seção, apresenta-se a base teórico-empírica sobre serviços, abrangendo sua relação com produtos, suas características, a percepção dos clientes e o modelo SERVQUAL.

\subsection{OS SERVIÇOS E SUA RELAÇÃO COM PRODUTOS}

Os serviços consistem em um conjunto de prestações esperadas pelos clientes que extrapolam o produto base (HOROVITZ, 1993). Kotler, Hayes e Bloom (2002) defendem R. eletr. estrat. neg., Florianópolis, v.5, n.1, p. 200-223, jan./abr. 2012 
que um serviço consiste em uma ação, um desempenho ou um ato que é essencialmente intangível e não acarreta, necessariamente, a propriedade do que quer que seja. Isso porque, segundo esses autores, um serviço pode ou não estar vinculado a um produto material.

Apesar dessas definições considerarem que os serviços podem estar vinculados a produtos e, dessa forma, não serem exclusividade de empresas conhecidas como prestadoras de serviços, as indústrias normalmente estão voltadas para a qualidade de seus produtos, esquecendo-se de enfocar, também, a qualidade dos serviços. Esta, por sua vez, ocorre por meio de uma série de operações, nas quais os serviços possuem, no que se refere à competitividade, importante papel. Nessa perspectiva, os serviços são considerados como todas as operações que acrescentam valor ao produto, dentro e fora da organização (CARDOSO, 1995).Carlzon e Lagerstrom (2005) afirmam que, cada vez mais, as empresas não conseguem obter vantagem por meio de seus produtos, necessitando investir em seus serviços. Segundo Cardoso (1995), nesse contexto, as empresas estão se orientando para serviços como uma oportunidade de diferencial competitivo. Assim, um serviço pode ser uma forma de ampliar a satisfação ou insatisfação com um produto, tornando-se um fator de sucesso ou de fracasso.

\subsection{CARACTERÍSTICAS DOS SERVIÇOS E PERCEPÇÃO DOS CLIENTES}

Para melhor compreender os serviços, Parasuraman, Zeithaml e Berry (1985) apresentam quatro características inerentes a eles, conforme o Quadro 1. Além disso, neste quadro, os autores apresentam os problemas de marketing decorrentes de cada característica dos serviços, bem como estratégias de marketing que podem ser empregadas para minimizar estes problemas. 
Quadro 1 - Características, problemas e estratégias na qualidade dos serviços

\begin{tabular}{|c|c|c|}
\hline Características & Problemas de marketing & Estratégias de marketing \\
\hline Intangibilidade & $\begin{array}{l}\text { - Serviços não podem ser provados ou } \\
\text { experimentados antes de serem } \\
\text { comprados. } \\
\text { - Não se podem proteger serviços por } \\
\text { meio de patentes. } \\
\text { - Não é possível prontamente dispor ou } \\
\text { comunicar serviços. } \\
\text { - Dificuldade para estabelecer preços. }\end{array}$ & $\begin{array}{l}\text { - Usar fontes pessoais. } \\
\text { - Simular ou estimular comunicações de } \\
\text { conversa boca a boca. } \\
\text { - Criar forte imagem organizacional. } \\
\text { - Usar contabilidade de custos para auxiliar a } \\
\text { fixação de preço. } \\
\text { - Informar, nas comunicações, postos de } \\
\text { compra. }\end{array}$ \\
\hline Inseparabilidade & $\begin{array}{l}\text { - Serviços são produzidos e consumidos } \\
\text { ao mesmo tempo, ou seja, o } \\
\text { consumidor está envolvido na } \\
\text { produção. } \\
\text { - Ações do consumidor afetam a } \\
\text { prestação do serviço. }\end{array}$ & $\begin{array}{l}\text { - Enfatizar seleção e treinamento dos } \\
\text { funcionários. } \\
\text { - Administrar consumidores. } \\
\text { - Usar localizações de multiposições. }\end{array}$ \\
\hline Heterogeneidade & $\begin{array}{l}\text { - Serviços são altamente variáveis à } \\
\text { medida que dependem de quem, } \\
\text { quando e onde são executados. }\end{array}$ & $\begin{array}{l}\text { - Industrializar serviços. } \\
\text { - Serviços customizados. }\end{array}$ \\
\hline Perecibilidade & $\begin{array}{l}\text { - Serviços não podem ser estocados, } \\
\text { pois a entrega é imediata e o sistema } \\
\text { de produção é sempre acionado pelo } \\
\text { cliente. }\end{array}$ & $\begin{array}{l}\text { - Estratégias para competir com flutuações na } \\
\text { demanda } \\
\text { - Ajustes simultâneos na demanda e na } \\
\text { capacidade produtiva. }\end{array}$ \\
\hline
\end{tabular}

Fonte: Adaptado de Parasuraman, Zeithaml e Berry, 1985.

As características particulares dos serviços, expostas no Quadro 1, têm implicações em como os clientes percebem sua qualidade. No Quadro 2, destacam-se os fatores que, de acordo com Parasuraman, Zeithaml e Berry (1985), influenciam a percepção dos clientes sobre um serviço.

Quadro 2 - Fatores que afetam a percepção e a avaliação da qualidade do serviço

\begin{tabular}{|l|l|}
\hline Fator & Descrição \\
\hline Acesso & Fácil contato, proximidade, instalações adequadas e tempo de espera. \\
\hline Comunicação & Ouvir sempre os clientes, mantê-los informados e empregar linguagem compreensível. \\
\hline Competência & Habilidades e conhecimentos requeridos para desempenhar o serviço. \\
\hline Cortesia & Respeito, educação, consideração e contatos amistosos. \\
\hline Credibilidade & Fidelidade, honestidade e confiança. \\
\hline Confiança & Consistência de desempenho, precisão e honrar compromissos. \\
\hline Receptividade & Prontidão e criatividade quanto às solicitações e aos problemas. \\
\hline Segurança & Não oferecer perigo, risco ou dúvida. \\
\hline Tangibilidade & Evidência física do serviço, dos equipamentos e dos materiais visuais. \\
\hline Compreensão & Compreensão do cliente e de suas necessidades. \\
\hline
\end{tabular}

Fonte: Adaptado de Parasuraman, Zeithaml e Berry, 1985.

Parasuraman, Zeithaml e Berry (1985) ressaltam que a percepção que os clientes possuem a respeito da qualidade de serviço ocorre a partir da comparação entre a qualidade 
esperada - as expectativas dos clientes a respeito da qualidade do serviço - e a qualidade experimentada - a efetiva percepção de qualidade do que foi ofertado. A qualidade esperada é anterior à realização do serviço, enquanto a experimentada é posterior.

Nesse mesmo sentido, o paradigma da desconformidade, de acordo com Johnston (1995), consiste na visão de que a satisfação do consumidor é determinada a partir da comparação entre a percepção do desempenho do produto ou serviço e a expectativa inicialmente estabelecida. Sendo assim, a satisfação do consumidor pode ser expressa como uma função das expectativas pré-compra e do desempenho pós-compra. Como Swan e Wick (1981) destacam, a satisfação dos clientes aumenta à medida que aumenta a desconfirmação positiva, ou seja, à medida que a percepção do desempenho excede as expectativas iniciais.

A partir dessa ideia de gap entre expectativa e percepção, Parasuraman, Zeithaml e Berry (1985) apresentam cinco falhas realizadas pelas empresas em relação a seus serviços: a) distância entre a expectativa do consumidor e a percepção da empresa sobre tal, em termos do quê e de como o cliente julga; b) distância entre a percepção da empresa e as especificações/padrões da qualidade do serviço; c) distância entre especificações da qualidade do serviço e sua execução (falta de treinamento, sobrecarga, baixo moral, equipamentos deficientes etc.); d) distância entre a execução do serviço e as comunicações externas, pois as expectativas de clientes são baseadas em promessas comunicadas pelo fornecedor; e) distância entre o serviço percebido e o esperado, que ocorre quando uma ou mais das anteriores ocorrem.

Para evitar essas falhas, é essencial que as organizações se aproximem de seus clientes, investigando como eles avaliam a qualidade dos serviços, pois este é um fator importante para identificar oportunidades estratégicas para as empresas. Isso pode auxiliar na definição de procedimentos e métodos para os serviços que transmitam eficiência e eficácia aos clientes (CARDOSO, 1995). 


\subsection{MODELO SERVQUAL}

Em seus estudos, Parasuraman, Zeithaml e Berry (1985) construíram um questionário com cerca de cem perguntas, no qual os clientes classificam um serviço com relação às expectativas e ao desempenho em fatores específicos. As perguntas construídas pelos autores se encontram organizadas em dez dimensões: a) confiabilidade (serviço desempenhado com consistência e precisão); b) presteza (rapidez e espontaneidade dos funcionários da empresa de serviço na solução de problemas dos consumidores); c) competência (funcionários possuem habilidades e conhecimentos para a execução do serviço); d) acesso (facilidade de contato e uso dos serviços); e) cortesia (funcionários corteses e respeitosos para com os consumidores); f) comunicação (serviço descrito acuradamente na linguagem do consumidor); g) credibilidade (empresa preza os interesses do consumidor, sendo digno de sua confiança); h) segurança (serviço não oferece perigo, risco ou dúvida); i) compreensão e conhecimento do consumidor (esforço para a compreensão das necessidades do consumidor pelos funcionários); e j) tangibilidade (evidências físicas do serviço que projetam a sua qualidade).

Em seguida, Parasuraman, Zeithaml e Berry (1985) analisaram os dados, agrupando um conjunto de perguntas que mediam a mesma dimensão básica, ou seja, o objetivo era determinar quais perguntas mediam cada uma das dimensões, quais não distinguiam as dimensões e qual o número de dimensões. Subsequentemente, os autores reformularam o questionário e o agruparam com uma nova amostra, na qual os itens das questões foram testados outra vez. Assim, os dez fatores foram reagrupados em cinco dimensões e o questionário ficou composto com quarenta e quatro questões, dando origem ao instrumento denominado SERVQUAL (PARASURAMAN; ZEITHAML; BERRY, 1988), que se tornou um dos métodos mais populares na medição da qualidade do serviço. Nele, analisase a qualidade percebida pelo cliente, destacando os pontos fortes e os que necessitam de melhorias no serviço. As cinco dimensões gerais que, de acordo com o modelo SERVQUAL, influenciam a qualidade do serviço prestado ao cliente são descritas no Quadro 3. 
QUALIDADE DOS SERVIÇOS EM INDÚSTRIA TÊXTIL: AVALIAÇÃO DE CLIENTES VAREJISTAS

Leomar dos Santos - Gildo José Koerich - Tatiana Marceda Bach - Silvana Anita Walter

Quadro 3 - Dimensões da qualidade do serviço segundo modelo SERVQUAL

\begin{tabular}{|l|l|}
\hline Dimensão & Descrição \\
\hline Tangível & $\begin{array}{l}\text { Aparência de instalações físicas, pessoal e materiais de comunicação, } \\
\text { equipamentos. }\end{array}$ \\
\hline Confiabilidade & $\begin{array}{l}\text { Capacidade de realizar o serviço prometido de modo confiável e com precisão, } \\
\text { satisfazendo as necessidades primárias de prazo e de qualidade dos clientes. }\end{array}$ \\
\hline $\begin{array}{l}\text { Capacidade } \\
\text { respostas }\end{array}$ & $\begin{array}{l}\text { Boa vontade, disposição para ajudar e com presteza, proporcionando um serviço } \\
\text { de nível. }\end{array}$ \\
\hline Segurança & Conhecimento e cortesia na transmissão de confiança e confiabilidade. \\
\hline Empatia & Cortesia, gentileza, apoio e atenção individualizada aos clientes. \\
\hline
\end{tabular}

Fonte: Adaptado de Parasuraman, Zeithaml e Berry, 1988.

O questionário SERVQUAL é constituído de duas seções, ou seja, uma possui 22 itens que visam a medir as expectativas dos clientes em relação às organizações de um ramo geral, e outra, 22 itens que medem as percepções do cliente com relação ao serviço de uma organização em particular. Para cada item de uma seção, existe um correspondente na outra. Assim, os itens refletem, em ambas as seções, as cinco dimensões. Esses itens são acompanhados por escalas de sete pontos, ancoradas por rótulos "discorda totalmente" (posição 1) e "concorda totalmente" (posição 7).

A partir desses dados, faz-se a mensuração do gap, que consiste em calcular a diferença entre as análises de cada afirmação nas seções denominadas de expectativas e percepções. Logo, quanto menores forem os gaps, mais próximas as expectativas e as percepções dos clientes estarão.

Como exemplos de estudos que empregaram o modelo SERVQUAL para avaliar a qualidade de serviços associados a produtos, podem-se citar o de Carvalho et al. (2008), de Mundin e August (2008) e de Silva (2011).

Carvalho et al. (2008) analisaram, por meio do modelo SERVQUAL, a qualidade dos serviços prestados por uma empresa distribuidora de produtos capilares. Os autores identificaram que as maiores expectativas estavam nas dimensões segurança, confiabilidade e receptividade (ou capacidade de respostas); porém, o maior gap entre expectativa e percepção foi na dimensão segurança, seguida das dimensões tangível (principalmente com relação a material de divulgação) e confiabilidade (principalmente com relação à capacidade dos funcionários de lidarem de maneira cuidadosa com os clientes). 
Mundin e August (2008), valendo-se das dimensões do modelo SERVQUAL, verificaram os gaps existentes entre expectativa e percepção de qualidade a respeito dos serviços de pós-venda de uma concessionária de automóveis. Os autores perceberam que, de maneira geral, os clientes se apresentaram satisfeitos com os serviços nas cinco dimensões avaliadas. Contudo, verificaram a existência de lacunas entre a expectativa e a percepção dos clientes no que se refere a algumas variáveis: preço, horário da oficina e reincidência de retornos para solucionar problemas de ruídos nos veículos.

Silva (2011) empregou a escala SERVQUAL para avaliar a qualidade dos serviços vinculados à compra de imóveis habitacionais. $\mathrm{O}$ autor identificou, como aspectos de maior importância para os clientes: transações serem imediatas; atendimento individualizado com conhecimento e cortesia; buscar entender e atender às necessidades e aos desejos dos clientes.

Como destacado anteriormente, não se identificaram, na literatura, estudos que analisassem a percepção que clientes varejistas de uma indústria têxtil possuem a respeito da qualidade dos serviços, como realiza esta pesquisa por meio da utilização do modelo SERQUAL.

\section{PROCEDIMENTOS METODOLÓGICOS}

Para responder aos objetivos propostos, realizou-se este estudo, que se caracteriza como descritivo quanto aos objetivos, e de levantamento quanto aos procedimentos. Segundo Hair et al. (2005), a pesquisa descritiva visa à descrição de determinada situação e pode fazer uso da mensuração de um evento ou de uma atividade. $O$ levantamento, de acordo com Gil (2009), consiste na coleta de informações perante um grupo significativo de pessoas e na obtenção das conclusões a partir de análise quantitativa. Quanto à abordagem do problema, a pesquisa é quantitativa.

Realizou-se a coleta de dados por meio de um questionário autoadministrado, de acordo com o modelo SERVQUAL de Parasuraman, Zeithaml e Berry (1988). O instrumento R. eletr. estrat. neg., Florianópolis, v.5, n.1, p. 200-223, jan./abr. 2012 
avalia, em uma escala de 1 ("discorda totalmente") a 7 ("concorda totalmente"), a percepção dos clientes varejistas a respeito de serviços prestados pela empresa avaliada, como atendimento por telefone e internet, bem como atendimento na sede da empresa para conhecer os produtos e realizar os pedidos; portal de informações sobre produtos e acompanhamento dos pedidos; emissão de notas fiscais e duplicatas; entrega dos pedidos; visitas de vendedores à sede dos clientes; fornecimento de informações e material para ações de publicidade; organização de eventos para apresentação dos produtos; serviços de pós-venda etc. Compuseram o questionário 44 questões, sendo metade sobre expectativa e metade sobre percepção de 22 atributos. Os atributos mensurados no questionário estão apresentados no Quadro 4.

Quadro 4 - Dimensões e atributos analisados

\begin{tabular}{|c|c|c|}
\hline Dimensões & Atr & itos \\
\hline \multirow{4}{*}{ Tangibilidade } & 1 & Equipamentos modernos \\
\hline & 2 & Instalações físicas visivelmente atraentes \\
\hline & 3 & Aparência dos funcionários \\
\hline & 4 & Aparência das instalações físicas \\
\hline \multirow{5}{*}{ Confiabilidade } & 5 & Cumprimento de prazos \\
\hline & 6 & Presteza na resolução de problemas \\
\hline & 7 & Confiabilidade da empresa \\
\hline & 8 & Fornecimento de serviços no prazo \\
\hline & 9 & Registros atualizados \\
\hline \multirow{4}{*}{ Capacidade de resposta } & 10 & Informar com exatidão o prazo de execução do serviço \\
\hline & 11 & Rapidez no atendimento \\
\hline & 12 & Vontade dos funcionários em ajudar \\
\hline & 13 & Prontidão nas respostas aos clientes \\
\hline \multirow{4}{*}{ Segurança } & 14 & Confiabilidade dos funcionários \\
\hline & 15 & Segurança nas transações com a empresa \\
\hline & 16 & Gentileza dos funcionários \\
\hline & 17 & Suporte da empresa para que os funcionários realizem o serviço \\
\hline \multirow{5}{*}{ Empatia } & 18 & Atenção individual aos clientes \\
\hline & 19 & Atenção personalizada ao cliente \\
\hline & 20 & Conhecimento das necessidades dos clientes \\
\hline & 21 & Interesse no bem-estar do cliente \\
\hline & 22 & Horário de atendimento adequado \\
\hline
\end{tabular}

Fonte: Parasuraman, Zeithaml e Berry, 1988.

Anteriormente ao início da coleta de dados por questionário, aplicou-se um préteste a cinco clientes que estavam em visita à empresa para avaliar a compreensão das questões. Estes clientes leram o questionário e indicaram aos pesquisadores se tinham 
alguma dúvida em relação às questões, à escala e ao objetivo do questionário. A partir dos seus relatos, fizeram-se algumas alterações no texto das instruções e das questões, visando a ampliar a compreensão dos respondentes.

Para obtenção dos respondentes, inicialmente foram identificados os clientes varejistas que realizavam compras frequentes na empresa pesquisada (ao menos seis compras nos últimos doze meses). Destes, verificou-se quais clientes e a pessoa vinculada a esses clientes (proprietário, gerente ou outro) que havia visitado as instalações da empresa analisada. A esse respeito, destaca-se que a empresa em questão oferece eventos em sua sede em cada lançamento de coleção. Assim, os clientes podem realizar visitas acompanhadas às instalações da indústria, conhecendo todos os processos fabris e administrativos. Esse foco nos indivíduos que visitaram a empresa pesquisada deve-se ao fato do questionário incluir a avaliação de aspectos tangíveis das instalações.

Como essa amostra abrangia 426 clientes de diferentes regiões do Brasil, realizou-se a coleta com o auxílio dos gerentes regionais de vendas. Cada gerente regional de vendas recebeu uma listagem dos respondentes e cópias dos questionários a serem respondidos. Destaca-se que os gerentes foram instruídos pessoalmente quanto às características da pesquisa e aos objetivos desejados. Dois meses após, 130 questionários haviam sido devolvidos com dados completos, os quais foram utilizados para as análises.

Durante a realização da pesquisa, realizaram-se visitas à empresa como forma de conhecer suas características, identificar os clientes que comporiam a amostra, apresentar a pesquisa aos gerentes regionais de vendas e realizar outros procedimentos necessários ao andamento da pesquisa. Também se realizaram consultas a documentos internos e ao site da organização para descrever a empresa analisada.

Para a análise dos dados, empregou-se estatística descritiva por meio das médias obtidas em relação à expectativa e à percepção da qualidade de atributos e dimensões. $O$ gap (diferença) existente entre o índice de expectativa e o de percepção em cada atributo foi verificado por meio do uso de estatística multivariada (teste t pareado), a qual visa a identificar diferenças estatisticamente significantes entre respostas oriundas da mesma população. 


\section{RESULTADOS}

Nesta seção, descreve-se a empresa analisada e os resultados obtidos por meio do emprego do modelo SERVQUAL.

\subsection{EMPRESA ANALISADA}

Nesta subseção, descreve-se a organização foco com os dados obtidos a partir da consulta ao site da empresa e a documentos internos.

A empresa pesquisada consiste em uma indústria familiar do ramo têxtil que, fundada na década de 1880 por dois irmãos, iniciou suas atividades como uma pequena tecelagem e, na década de 1890, obteve juridicamente o porte de empresa. Na década de 1910, a empresa estabeleceu uma fiação, passando a produzir, também, fio de algodão. A partir da década de 1920, estabeleceu novas unidades em outros municípios da região e se tornou uma sociedade por ações. Já a partir da década de 1960, deu início à exportação de produtos. Ainda nesse período, experimentou grande impulso expansivo, iniciando um programa de reorganização, modernização e ampliação de todo o parque industrial, o que a tornou, em seu ramo, a maior da América Latina. Na década de 1970, lançou uma marca destinada ao público infantil e criou novas unidades no sul e no nordeste do Brasil. Na década de 1990, atingida pela desvalorização cambial do dólar, optou por ampliar seu capital por meio da subscrição pública, com entrada de novos acionistas. A partir disso, uma reestruturação operacional, do passivo financeiro e comercial (novas marcas e canais de distribuição) iniciou-se. Algumas das novidades nesse período foram a criação de franquias para comercialização das marcas da empresa, do Serviço de Atendimento ao Consumidor e do Sistema de Gestão Ambiental. Na década de 2000, ocorreu uma nova reestruturação organizacional das unidades de negócios, com foco nas marcas próprias, na contratação de uma empresa de consultoria na área de planejamento estratégico, no ingresso na carteira do índice de ações com governança coorporativa diferenciada da BOVESPA e no desenvolvimento de um novo projeto arquitetônico para as franquias da empresa. 
Atualmente, a empresa emprega cerca de 4.200 pessoas e está hierarquicamente organizada em conselho administrativo, presidência, diretorias (administrativa; comercial; cadeia de suprimentos e logística; marketing e produto; financeira; e industrial) e 29 gerências em diversas áreas, sendo quatro administrativas, dez comerciais, quatro na área de logística, cinco em marketing e cinco de produção. No tocante à relação entre participação familiar e profissionalização, destaca-se que o presidente e o diretor administrativo são membros da família e os demais diretores são profissionais não pertencentes à família.

A empresa possui cerca de 180 lojas que comercializam exclusivamente suas marcas, além de mais de 9.000 pontos de venda (lojas que também comercializam outras marcas). A empresa igualmente possui cerca de 20 franquias no exterior (América Latina e Oriente Médio). O faturamento estimado para 2011 é de R\$ 1 bilhão/ano.

\subsection{QUALIDADE DOS SERVIÇOS}

Nesta subseção, destacam-se os resultados obtidos por meio do questionário sobre a qualidade dos serviços prestados aos clientes varejistas. Na Figura 1, têm-se as médias obtidas para a expectativa e para a percepção dos 22 atributos de qualidade analisados. 
Figura 1 - Expectativa e percepção dos atributos de qualidade dos serviços

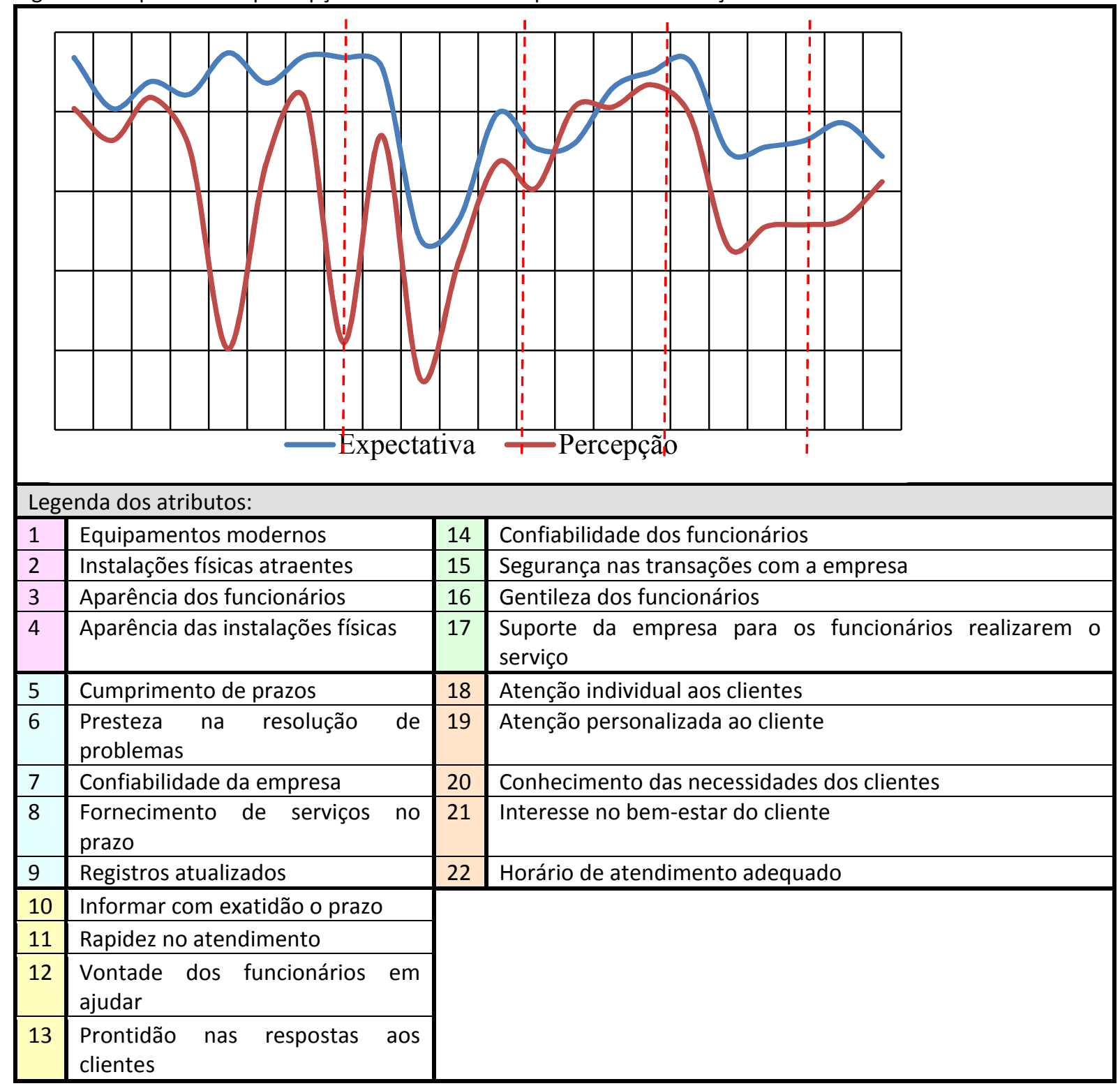

Fonte: Elaborado pelos autores, 2011.

Por meio da Figura 1, fica evidenciado que a percepção da qualidade superou a expectativa no atributo confiabilidade dos funcionários (14), que pertence à dimensão segurança. Isso revela que, nesse atributo, a empresa analisada extrapola o que os clientes esperaram de empresas do ramo. Esse resultado é importante porque, como destaca Parasuraman, Zeithaml e Berry (1985), a prestação dos serviços sofre variação visto que uma de suas características é a heterogeneidade. Assim, a confiabilidade dos funcionários tornase um importante fator de percepção da qualidade dos serviços. 
Também se percebe que expectativa e percepção são mais baixas no atributo informar com exatidão o prazo (10), da dimensão capacidade de resposta, o que indica que os clientes possivelmente percebem a dificuldade que as empresas encontram em estipular um prazo exato para realização de um serviço, visto que essa dificuldade está relacionada com as próprias características dos serviços de heterogeneidade e perecibilidade (PARASURAMAN, ZEITHAML; BERRY, 1985).

Na Tabela 1, destacam-se os resultados obtidos agrupados nas dimensões do modelo SERVQUAL.

Tabela 1 - Expectativa e percepção das dimensões de qualidade dos serviços

\begin{tabular}{l|c|c|c|c}
\multicolumn{1}{c|}{ Dimensões } & Atributos & Expectativa & Percepção & Gap \\
\hline \multicolumn{1}{c|}{ Tangibilidade } & 1 a 4 & 6,67 & 6,43 & $-0,24$ \\
\hline Confiabilidade & 5 a 9 & 6,80 & 5,83 & $-0,97$ \\
\hline Capacidade de resposta & 10 a 13 & 6,07 & 5,65 & $-0,42$ \\
\hline Segurança & 14 a 17 & 6,63 & 6,55 & $-0,08$ \\
\hline Empatia & 18 a 22 & 6,30 & 5,82 & $-0,48$ \\
\hline
\end{tabular}

Fonte: Elaborado pelos autores, 2011.

Como destacado por meio da Tabela 1, todas as dimensões apresentaram um gap negativo entre expectativa e percepção da qualidade dos serviços, demonstrando que os respondentes possuem uma expectativa mais elevada em relação às empresas do setor do que o que percebem no tocante à empresa pesquisada.

A dimensão com menor gap entre expectativa e percepção de qualidade foi segurança, ao contrário do encontrado por Carvalho et al. (2008). Nota-se que essa dimensão apresenta o maior índice de percepção de qualidade entre os respondentes.

Em contraposição, a dimensão que apresentou o maior gap entre expectativa e percepção de qualidade foi confiabilidade. Essa dimensão apresentou um gap elevado também na pesquisa de Carvalho et al. (2008). Tem-se, ainda, que essa dimensão exibe o maior índice de expectativa entre as avaliadas, o que também corrobora o encontrado por Carvalho et al. (2008).

$\mathrm{Na}$ Tabela 2, destaca-se o resultado do teste $\mathrm{t}$ pareado entre expectativa e percepção dos atributos analisados. 
Tabela 2 - Teste t pareado entre expectativa e percepção para os atributos avaliados

\begin{tabular}{|c|c|c|c|c|c|c|c|c|c|}
\hline \multirow{2}{*}{\multicolumn{2}{|c|}{ Atributos }} & \multicolumn{2}{|c|}{ Percepção } & \multicolumn{2}{|c|}{ Expectativa } & \multirow{2}{*}{ 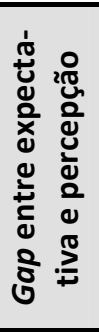 } & \multirow{2}{*}{ 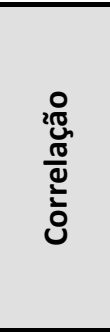 } & \multirow{2}{*}{$\begin{array}{l}\frac{0}{5} \\
0 \\
0 \\
0 \\
0 \\
0 \\
\frac{20}{0} \\
\frac{0}{0} \\
0 \\
0 \\
\frac{0}{3} \\
0 \\
0 \\
0\end{array}$} & \multirow[b]{2}{*}{$\mathbf{t}$} \\
\hline & & \multirow{2}{*}{ 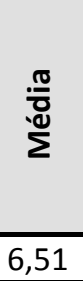 } & \multirow{2}{*}{ 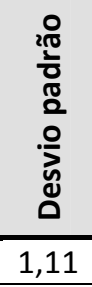 } & \multirow{2}{*}{\begin{tabular}{|c|}
$\frac{\pi}{7}$ \\
\multirow{2}{*}{} \\
6,72 \\
\end{tabular}} & \multirow{2}{*}{ 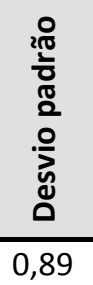 } & & & & \\
\hline 1 & Equipamentos modernos & & & & & 0,21 & 0,09 & 1,36 & $1,76^{*}$ \\
\hline 2 & Instalações físicas atraentes & 6,33 & 1,28 & 6,50 & 1,44 & 0,17 & $-0,05$ & 1,97 & 0,99 \\
\hline 3 & Aparência dos funcionários & 6,58 & 1,21 & 6,63 & 0,90 & 0,05 & $-0,02$ & 1,52 & 0,37 \\
\hline 4 & Aparência das instalações físicas & 6,38 & 1,36 & 6,60 & 1,25 & 0,22 & 0,38 & 1,45 & $1,73^{*}$ \\
\hline 5 & Cumprimento de prazos & 5,00 & 2,55 & 6,85 & 0,87 & 1,85 & $-0,02$ & 2,71 & $7,79 * *$ \\
\hline 6 & Presteza na resolução de problemas & 6,20 & 1,37 & 6,70 & 1,08 & 0,50 & 0,57 & 1,17 & $4,89 * *$ \\
\hline 7 & Confiabilidade da empresa & 6,60 & 1,07 & 6,83 & 0,76 & 0,23 & 0,17 & 1,20 & $2,18 * *$ \\
\hline 8 & Fornecimento de serviços no prazo & 5,00 & 2,24 & 6,80 & 0,96 & 1,80 & 0,04 & 2,41 & $8,52 * *$ \\
\hline 9 & Registros atualizados & 6,40 & 1,19 & 6,75 & 0,87 & 0,35 & 0,40 & 1,16 & $3,44 * *$ \\
\hline 10 & Informar com exatidão o prazo & 4,80 & 2,64 & 5,70 & 1,78 & 0,90 & $-0,19$ & 3,46 & $2,96 * *$ \\
\hline 11 & Rapidez no atendimento & 5,55 & 1,92 & 5,80 & 1,65 & 0,25 & $-0,16$ & 2,73 & 1,04 \\
\hline 12 & Vontade dos funcionários em ajudar & 6,25 & 1,50 & 6,50 & 1,25 & 0,25 & $-0,09$ & 2,04 & 1,39 \\
\hline 13 & Prontidão nas respostas aos clientes & 6,00 & 1,57 & 6,30 & 1,08 & 0,30 & 0,13 & 1,79 & $1,91^{*}$ \\
\hline 14 & Confiabilidade dos funcionários & 6,51 & 1,27 & 6,32 & 1,35 & 0,19 & $-0,30$ & 2,11 & 1,03 \\
\hline 15 & $\begin{array}{l}\text { Segurança nas transações com a } \\
\text { empresa }\end{array}$ & 6,52 & 1,13 & 6,60 & 0,93 & 0,08 & $-0,65$ & 1,87 & 0,49 \\
\hline 16 & Gentileza dos funcionários & 6,65 & 1,07 & 6,75 & 1,07 & 0,10 & $-0,16$ & 1,62 & 0,70 \\
\hline 17 & $\begin{array}{l}\text { Suporte da empresa para os funcionários } \\
\text { realizarem o serviço }\end{array}$ & 6,50 & 1,17 & 6,80 & 0,83 & 0,30 & $-0,35$ & 1,65 & $2,07 * *$ \\
\hline 18 & Atenção individual aos clientes & 5,60 & 1,88 & 6,25 & 1,58 & 0,65 & $-0,26$ & 2,76 & $2,68 * *$ \\
\hline 19 & Atenção personalizada ao cliente & 5,80 & 1,80 & 6,30 & 1,28 & 0,50 & $-0,22$ & 2,43 & $2,34 * *$ \\
\hline 20 & $\begin{array}{l}\text { Conhecimento das necessidades dos } \\
\text { clientes }\end{array}$ & 5,82 & 1,73 & 6,35 & 1,57 & 0,53 & 0,15 & 2,15 & $2,81 * *$ \\
\hline 21 & Interesse no bem-estar do cliente & 5,83 & 1,64 & 6,45 & 1,40 & 0,62 & 0,04 & 2,11 & $3,35 * *$ \\
\hline 22 & Horário de atendimento adequado & 6,05 & 1,46 & 6,22 & 1,26 & 0,17 & 0,28 & 1,64 & 1,18 \\
\hline \multicolumn{3}{|c|}{ * Significante a $10 \%$} & \multicolumn{7}{|c|}{ ** Significante a $5 \%$} \\
\hline
\end{tabular}

Fonte: Elaborado pelos autores, 2011.

Na Tabela 2, observa-se que os gaps encontrados entre expectativa e percepção nos atributos instalações físicas atraentes (2), aparência dos funcionários (3), rapidez no atendimento (11), vontade dos funcionários em ajudar (12), confiabilidade dos funcionários (14), segurança nas transações com a empresa (15), gentileza dos funcionários (16) e horário de atendimento adequado (22) não apresentaram diferença estatisticamente significante. Assim, destaca-se que nestes atributos os clientes varejistas da empresa pesquisada estão tendo uma percepção de qualidade bem próxima às suas expectativas em relação a empresas do ramo. Destaca-se, portanto, que, apesar do atributo confiabilidade dos 
funcionários (14) ter apresentado percepção acima da expectativa, essa diferença não é estaticamente significante.

Os atributos instalações físicas atraentes e aparência dos funcionários faz parte da dimensão tangibilidade. De acordo com Parasuraman, Zeithaml e Berry (1985), esses serviços são intangíveis, pois não podem ser experimentados antes da compra. Assim, as empresas necessitam desenvolver estratégias para atribuir tangibilidade a seus serviços, criando uma forte imagem organizacional, o que inclui a aparência dos funcionários.

Rapidez no atendimento e vontade dos funcionários em ajudar, por sua vez, agrupam-se na dimensão capacidade de resposta. Como destacam Parasuraman, Zeithaml e Berry (1988), a capacidade de resposta é um fator importante para proporcionar um serviço de nível elevado.

Já os atributos confiabilidade dos funcionários, gentileza dos funcionários e segurança nas transações com a empresa integram a dimensão segurança. Para Parasuraman, Zeithaml e Berry (1985), a cortesia no atendimento aos clientes e a segurança transmitida pela empresa (não oferecer perigo, risco ou dúvida) são fatores que influenciam a percepção dos clientes sobre um serviço. Silva (2011) identificou, em seu estudo, que um dos aspectos de maior importância para os clientes é o atendimento individualizado com conhecimento e cortesia.

Por fim, o atributo horário de atendimento adequado compõe a dimensão empatia. Em contraposição ao observado neste estudo, Mundin e August (2008) identificaram uma lacuna entre expectativa e percepção no horário de atendimento da empresa por eles pesquisada.

Por outro lado, tem-se que todos os gaps entre expectativa e percepção dos atributos que integram a dimensão confiabilidade (atributos 5 a 9) apresentaram diferença estatisticamente significante. Ressalta-se também que os dois maiores gaps encontrados são de dois atributos desta dimensão: cumprimento de prazos (5) com 1,85 e fornecimento de serviços no prazo (8) com 1,8. Percebe-se, assim, que a confiabilidade da empresa perante seus clientes varejistas está sendo prejudicada pela dificuldade em cumprir prazos, tanto em geral quanto na prestação dos serviços. Para Parasuraman, Zeithaml e Berry (1985), uma das dificuldades na prestação dos serviços ocorre pela perecibilidade dos serviços, visto que não R. eletr. estrat. neg., Florianópolis, v.5, n.1, p. 200-223, jan./abr. 2012 
podem ser estocados. Na pesquisa de Silva (2011), transações serem imediatas figurou entre as variáveis consideradas mais importantes para os clientes. Para minimizar esse problema, Parasuraman, Zeithaml e Berry (1985) sugerem que as empresas adotem estratégias para competir com flutuações na demanda e realizem ajustes simultâneos entre demanda e capacidade produtiva. Acredita-se que o que mais tenha contribuído com o alto gap entre as expectativas e a percepção das atividades que envolvem a dimensão confiabilidade seja o acúmulo de faturamento da empresa nos últimos dias de cada mês. Alguns casos de não sincronismo entre a área de vendas e as áreas responsáveis pela elaboração dos produtos causam atraso na entrega dos pedidos solicitados pelos clientes.

Além disso, na dimensão empatia (atributos 18 a 22), apenas um atributo não apresentou diferença estatisticamente significante entre expectativa e percepção. Segundo Parasuraman, Zeithaml e Berry (1988), a empatia abrange cortesia, gentileza, apoio e atenção individualizada aos clientes.

\section{CONSIDERAÇÕES FINAIS}

Desenvolveu-se esta pesquisa visando a verificar qual a percepção dos clientes varejistas de uma indústria do setor têxtil a respeito da qualidade dos serviços por ela prestados. Utilizou-se, para mensuração da qualidade percebida dos serviços, o modelo SERVQUAL, o qual permitiu identificar os gaps existentes entre expectativa e percepção da qualidade. Dessa forma, destacaram-se as dimensões confiabilidade e empatia por apresentarem gaps estatisticamente significantes na maioria de seus atributos.

A identificação destes gaps pode auxiliar a empresa a definir prioridades e ações de melhoria para ampliar a satisfação de seus clientes. Nesse sentido, identificaram-se como prioridades de melhoria, a dimensão confiabilidade e, principalmente, os atributos cumprimento de prazos e fornecimento de serviços no prazo.

Além disso, este estudo também pode contribuir para que a empresa implante critérios explícitos de qualidade na prestação de serviços. Acredita-se que a boa prestação R. eletr. estrat. neg., Florianópolis, v.5, n.1, p. 200-223, jan./abr. 2012 
dos serviços com a satisfação das expectativas dos clientes varejistas possa se refletir na satisfação das expectativas dos consumidores dos produtos da organização.

A partir da pesquisa realizada, podem-se apresentar algumas sugestões de implicações gerenciais para a empresa pesquisada:

a) supervisão dos representantes por meio de um sistema de acompanhamento de roteiro: o representante realiza o planejamento ou roteiro de viagem, repassa para o supervisor e para o gerente de vendas para que estes possam melhor gerenciar os fluxos de vendas.

b) disponibilização de consultas remotas para os representantes terem acesso às informações corporativas que dizem respeito à sua carteira de clientes. Assim, cria-se a possibilidade de planejar melhor o roteiro de viagem e fornecer informações precisas quanto às situações dos pedidos e notas fiscais.

c) atuação do representante como consultor de varejo, ou seja, o representante atua como aliado do cliente no intuito de ajudá-lo a melhor administrar o seu giro dos estoques e, consequentemente, aumentar as vendas e a rentabilidade. O representante não pode atuar como uma pessoa que satura o cliente de mercadorias as quais, futuramente, podem contribuir com os maus resultados da loja.

d) ampliar as oportunidades nas quais os clientes possam visitar o parque fabril da empresa para aumentar a empatia. Com isso, os laços de relacionamento ficam mais estreitos, e a empresa tem a oportunidade de receber informações úteis do mercado quanto à produção e qualidade.

e) revisão das rotinas de informática quanto aos critérios de produção e faturamento, visto que os sistemas de controle e a programação da produção, bem como os sistemas de entrada de pedidos, atendimento e faturamento, têm, em média, dez anos de existência. Os sistemas transacionais possuem muitas regras de negócios implícitas em seus comandos, tornando-se indispensável a revisão dessas rotinas para a verificação da validade das mesmas quanto ao contexto atual da companhia. Essa recomendação é essencial como 
procedimento para a redução do gap percebido nos atributos cumprimento de prazos e fornecimento de serviços no prazo.

f) desenvolvimento de pesquisas de expectativas e percepção da qualidade dos serviços prestados e dos produtos da empresa.

A partir do apresentado, espera-se contribuir para o conhecimento da área por meio da análise dos gaps estatisticamente significantes entre expectativa e percepção dos clientes varejistas a respeitos dos serviços associados a produtos de uma indústria têxtil. A esse respeito, os resultados sugerem que, das dimensões do modelo SERVQUAL, confiabilidade e empatia apresentam gaps estatisticamente significantes nos atributos avaliados.

Destaca-se, ainda, que, apesar de esta pesquisa apresentar a limitação de que seus resultados não possam ser generalizados para outras empresas, acredita-se que essa análise possa contribuir para o conhecimento sobre os serviços prestados por indústrias do ramo têxtil, como a alta expectativa dos clientes varejistas na confiabilidade de empresas desse setor. Assim, sugere-se que sejam realizadas pesquisas em outras empresas do ramo a respeito da qualidade dos serviços prestados, empregando o modelo SEVQUAL e/ou outras ferramentas de mensuração da qualidade percebida de serviços.

Outra possibilidade para pesquisas futuras seria aprofundar as investigações, qualitativamente, nas dimensões que apresentaram maior gap, que foram confiabilidade e empatia, para indicar como e por que este gap se manifesta. Sugere-se ainda que em estudos futuros sejam analisados quais serviços de uma indústria têxtil mais afetam a percepção da qualidade ou a satisfação de seus clientes, o que poderia ser analisado utilizando técnicas não lineares como Análise do Contraste da Penalidade e da Recompensa (PRC) ou Modelo Kano de Qualidade Atrativa e Obrigatória. 


\section{QUALITY OF SERVICE IN TEXTILE INDUSTRY: EVALUATION OF CUSTOMERS RETAILERS}

\section{ABSTRACT}

This study aims to analyze the perception of the retail customers of a textile industry about the quality of services. Some studies have investigated the perception of quality of textile products, but are still incipient the studies that analyze the perceived quality of services provided by these companies. Researches of this nature become important because, besides of producing and marketing products, the textile industries also operate in providing various services to its customers, even those integrated in the sale of household products. The quality of these services can make a difference on how these companies obtain the satisfaction of its customers, adding value to products. We conducted a survey with the application of a structured questionnaire based on SERVQUAL model, on 130 retail customers of a textile company. For data analysis, descriptive statistics was used to identify the gaps in the analysis of this model. The SERVQUAL model has identified the major gaps between expectation and perception of quality, which can assist the company in defining priorities and actions for improvement. In this sense, are presented some managerial implications for the company studied. This study also intends to help the organization on implementing explicit criteria of quality in service delivery.

Key-words: quality of Services. SERVQUAL. The Textile Industry.

\section{REFERÊNCIAS}

CARDOSO, Olga R. Foco da qualidade total de serviços no conceito de produto ampliado. 1995. 402 f. Tese (Doutorado em Engenharia de Produção)-Programa de Pós-Graduação em Engenharia de Produção, Universidade Federal de Santa Catarina, Florianópolis, 1995.

CARLZON, Jan; LAGERSTROM, Tomas. A hora da verdade. Rio de Janeiro: Sextante, 2005. 
CARVALHO, Andriele P. et al. Aplicação do Modelo SERVQUAL de avaliação da qualidade na distribuidora Bio Extratus. Synergimus Scyentifica, v. 3, n. 1, p. 1-6, 2008.

CRONIN, Joseph; TAYLOR, Steven. Measuring service quality: a reexamination and extension. Journal of Marketing, v. 56, n. 3, 1992.

GIL, Antonio C. Métodos e técnicas de pesquisa social. 6. ed. São Paulo: Atlas, 2009.

HAIR JR., Joseph F. et al. Análise multivariada de dados. 5. ed. Porto Alegre: Bookman, 2005.

HAYES, Bob E. Medindo a satisfação do cliente: desenvolvimento e uso de questionários. Rio de Janeiro: Qualitymark, 2001.

HOROVITZ, Jaques. Qualidade de serviço: a batalha pela conquista do cliente. São Paulo: Nobel, 1993.

HUGHEY, David; CHAWLA, Sudhir; KHAN, Zafar. Measuring the quality of university computer labs using Servqual: a longitudinal study. The Quality Management Journal, v. 10, n. 3, p. 3344, 2003.

JOHNSTON, David M. Mensuração da qualidade de serviços através da escala Servqual: sua operacionalização no setor de serviços bancários business-to-business. 1995. $120 \mathrm{f}$. Dissertação (Mestrado em Administração)-Programa de Pós-Graduação em Administração, Universidade Federal do Rio Grande do Sul, Porto Alegre, 1995.

KOTLER, Philip; HAYES, Thomas; BLOOM, Paul N. Marketing de serviços profissionais: estratégias inovadoras para impulsionar sua atividade, sua imagem e seus lucros. 2. ed. São Paulo: Manole, 2002.

LOPES, Evandro L.; HERNANDEZ, José M. C.; NOHARA, Jouliana J. Escalas concorrentes para a mensuração da qualidade percebida: uma comparação entre a Servqual e a RSQ. Revista de Administração de Empresas, São Paulo, v. 49, n. 4, out./dez. 2009.

MASSUDA, Ely M. Transformações recentes da indústria têxtil brasileira (1992-1999). Acta Scientiarum, v. 24, n. 1, p. 243-251, 2002.

MOREIRA, Sérgio D. Percepção da qualidade e uso competitivo de tecnologia de informação em empresas têxteis e de confecção de "Jeanswear". 176 f. 2004. Dissertação (Mestrado Profissional em Sistema de Gestão)-Universidade Federal Fluminense, Niterói, RJ, 2004.

MUNDIM, Rodrigo S. A.; AUGUST, Débora R. Análise de gaps da qualidade no pós-venda da concessionária Le Monde Citroën - Blumenau. Revista Interdisciplinar Científica Aplicada, Blumenau, v. 2, n. 2, p. 01-28, 2008. 
PARASURAMAN, A.; ZEITHAML, Valarie A.; BERRY, Leonard L. A conceptual model of service quality and its implications for future research. Journal of Marketing, v. 49, p. 41-50, 1985.

. SERVQUAL: A multi-item scale for measuring consumer perceptions of service quality. Journal of Retailing, v. 64, n. 1, p. 12-40, 1988.

QUINTELLA, Heitor L. M. M.; MOREIRA, Sérgio D.; SILVA, Vagner R. Qualidade percebida e tecnologia de informação na indústria de Jeanswear. Tendências do Trabalho, v. 358, p. 3034, jun. 2004.

SILVA, Marcelo B. C. da. Adaptação da escala SERVQUAL para avaliação da qualidade dos serviços no contexto da construção de edificações multifamiliares. 2011. 147 f. Dissertação (Mestrado em Administração)-Programa de Pós-Graduação em Administração, Universidade de Caxias do Sul, Caxias do Sul, 2011.

SWAN, John E.; WICK, I. Frederick T. Disconfirmation of expectations and satisfaction with a retail service. Journal of Retailing, v. 57, n. 3, 1981.

TEAS, R. Expectations as comparison standard in measuring service quality: an assessment of a reassessment. Journal of Marketing, v. 58, n. 1, 1994. 